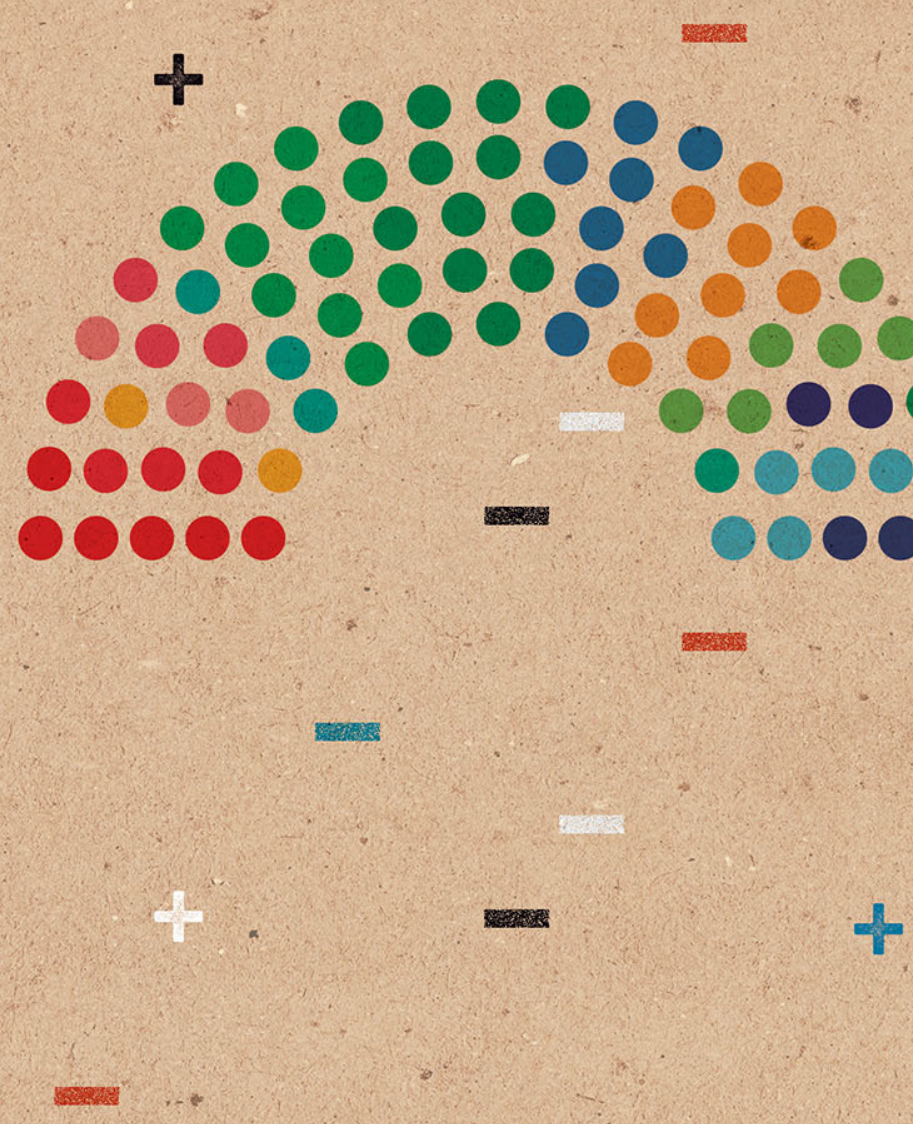

000000000000

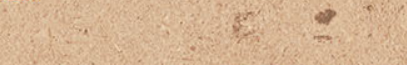

20090901 0000000000 000000000000 -00000000000 000000000 10000909090 

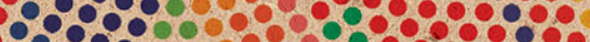
-

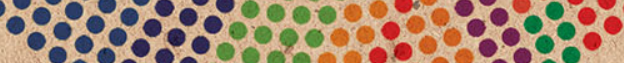
2

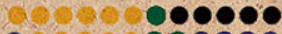
-

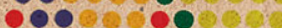
- 10 o 2000 - 000000 


\title{
Fragmentação e convergências: $a$ agenda da inovação da Câmara e no Senado
}

\section{Fragmentation and convergence: the innovation agenda in the Brazilion Congress and Senate}

\author{
Ricardo Lopes da Luz Korb* \\ Moisés Balestro**
}

\begin{abstract}
Resumo
O propósito deste artigo é analisar em que medida houve convergências e divergências em torno da pauta de inovação. O pressuposto teórico da relevância da convergência em torno da agenda de inovação está relacionado com o conceito de convenção tal como estabelecido por Erber (2004) na relação entre inovação e a convenção de desenvolvimento. As convenções constituem um conjunto de crenças partilhadas por uma comunidade (neste caso a comunidade das elites políticas no parlamento) para estabelecer o contexto do problema, os caminhos para a solução dos problemas. A convenção constitui um dispositivo heurístico para lidar com a incerteza. As convenções se assemelham aos paradigmas de Kuhn (1971) no que diz respeito à escolha dos problemas, ao repertório de técnicas procedimentos validados na comunidade para a busca de soluções.

Em termos analíticos, são levadas em conta as contribuições do institucionalismo discursivo. A análise dos discursos dos parlamentares em torno de uma agenda de inovação também permite entender melhor a formação das preferências dos atores. De acordo com as contribuições do institucionalismo centradono ator (actor-centred institutionalism), há quatro elementos que ajudam a entender a formação de preferências (Treib, 2015). O primeiro se refere aos próprios interesses institucionais das organizações ou dos partidos como crescimento, força e poder (ainda que no caso brasileiro os partidos sejam fracos e as bancadas são estruturadas em função de grupos de interesse relacionados aos processos de lobby).
\end{abstract}

Palavras-chave: convenção, desenvolvimento, inovação, parlamentares

\begin{abstract}
The purpose of this paper is to ponder the extent of convergences and divergences around the innovation agenda. The theoretical assumption of the relevance of convergence around the innovation agenda is related to the concept of convention, as established by Erber (2004) in the relationship between innovation and the development convention. Conventions constitute a set of beliefs shared by a community (in this case, the community of political elites in parliament) to establish the context and ways of solving problems Convention is a heuristic device for dealing with uncertainty. The conventions resemble Kuhn's (1971) paradigms regarding the understanding of problems and the repertoire of validated procedural techniques in the community in the search for solutions. In analytical terms, the article considers contributions of discursive institutionalism. The analysis of parliamentarians' speeches around an innovation agenda also allows us to understand the formation of the actors' preferences better. According to the contributions of actor-centered institutionalism, four elements help to understand preference formation (Treib, 2015). The first refers to the organizations or the party's institutional interests, such as growth, strength, and power (although in the Brazilian case parties are weak, and individual mandates respond to lobbyingrelated interest groups).
\end{abstract}

Keywords: Innovation, Conventions, Development, Senate, Camara.

\footnotetext{
* Graduação em agronegócios, Universidade de Brasília. E-mail: rllkorb@gmail.com

** Professor do Centro de Pesquisa e Pós-Graduação sobre as Américas, Universidade de Brasília. E-mail: mvbalestro@gmail.com
} 


\section{INTRODUÇÃO}

Um dos elementos motivadores deste artigo foi perceber a estabilidade política e suprapartidária dos temas relacionados com a inovação na experiência da Alemanha. A estabilidade não deriva do fato de que o partido do governo mantém maioria naquele regime parlamentar, mas de que os grandes programas envolvendo inovação e ciência são construídos quase sempre de forma consensual com todos os partidos políticos, sejam eles de situação ou de oposição. A partir desta percepção com base em relatórios e entrevistas em profundidade realizadas em ministérios na Alemanha, surgiu a indagação de qual seria o grau de consenso e de convergência ideacional e política em torno de temas relacionadas com a construção de uma agenda da inovação no parlamento brasileiro. Para isso, foram analisados 521 discursos de senadores e 430 discursos de deputados no período de 2008 a 2018. Nestes dez anos, foram implementadas as duas grandes políticas industriais, o Programa de Desenvolvimento Produtivo (PDP) e o Plano Brasil Maior (PBM), bem como o forte aumento do financiamento ao desenvolvimento industrial e da própria inovação com o BNDES ${ }^{1}$, o Programa InovaEmpresa e o aumento da cateira de projetos da FINEP, de 293 milhões em 2008 para 2,4 bilhões em $2014^{2}$.

A discussão recente sobre inovação tecnológica no Brasil esteve atrelada aos problemas de competitividade da base de manufatura do país, especialmente nos últimos 15 anos, quandohouve um reinício deuma discussão mais objetiva a respeito de Políticas Industriais. No período dos governos de Fernando Henrique Cardoso, as iniciativas de política industrial foram tímidas e elas surgiram no segundo mandato (1997-2001), com destaque para a criação dos fundos setoriais em 1999. Já nos governos Lula e Dilma, o tema e a materialização das políticas industriais surgiram de maneira mais explícita com a PITCE (Política Industrial Tecnológica e de Comércio Exterior), mais horizontal e seletiva, e com a PDP (Política de Desenvolvimento Produtivo), mais vertical e abrangente nos setores atendidos. Percebe-se, portanto, que entre um governo e outro, diversas ideias são alteradas, o que pode criar uma tendência à descontinuidade de políticas iniciadas por outros governos, como foi percebido com as diferenças entre Lula e Dilma. A partir de abril de 2016, a ruptura institucional produzida pelo golpe parlamentar na forma de impeachment cria situação de descontinuidade profunda. Não apenas programas foram descontinuados, mas a própria ideia de política industrial foi abandonada.

Para Cassiolato e Lastres (2015), nosúltimos 25 anos, a hegemonia da visão neoliberal em muito contribuiu para reduzir a complexidade do debate sobre desenvolvimento - e sobre o papel do planejamento de longo prazo e dos projetos nacionais - a uma agenda centrada na eliminação dos obstáculos ao livre funcionamento do mercado. O ideário neoliberal se apresenta como um continuum no espectro partidário dos partidos mais relevantes no cenário político dos últimos dez anos. São eles o PT, o PSDB e o PMDB. Mais recentemente, percebe-se a ascensão política de grupos tipicamente neoliberais como o Partido Novo nas eleições presidenciais de 2018. 
Um componente estrutural para as políticas públicas relacionadas com a agenda da inovação em países da América Latina é o que Fábio Erber chama de políticas implícitas (Cassiolato e Lastres, 2014). Por políticas implícitas, são entendidas as condições políticas e econômicas que orientam e servem de incentivos para as ações das empresas e do Estado.

A não-consideração das políticas implícitas pode ser a causa de paradoxo das políticas de inovação no Brasil. Ou seja, as políticas são bem desenhadas e dispõem de recursos para sua implementação, mas não são bem sucedidas em razão da relativa falta de receptividade do setor produtivo (Cassiolato e Lastres, 2014). No caso do período mais recente das políticas industriais, chama atenção as condições macroeconômicas desfavoráveis com taxas de câmbio elevadas e taxas de juros altas que não apenas afetam o financiamento do setor produtivo, mas também constituem um desincentivo aos investimentos em manufatura.

O propósito deste artigo é analisar em que medida houve convergências e divergências em torno da pauta de inovação. O pressuposto teórico da relevância da convergência em torno da agenda de inovação está relacionado com o conceito de convenção tal como estabelecido por Erber (2004) na relação entre inovação e a convenção de desenvolvimento. As convenções constituem um conjunto de crenças partilhadas por uma comunidade (neste caso a comunidade das elites políticas no parlamento) para estabelecer o contexto do problema, os caminhos para a solução dos problemas. A convenção constitui um dispositivo heurístico para lidar com a incerteza. As convenções se assemelham aos paradigmas de Kuhn (1971) no que diz respeito à escolha dos problemas, ao repertório de técnicas procedimentos validados na comunidade para a busca de soluções.

Em termos analíticos, são levadas em conta as contribuições do institucionalismo discursivo. Tal institucionalismo permite trazer o nível de coordenação e comunicação entre diferentes autores, sendo pertinente uma análise dessa natureza quando se trata de política, conforme Schmidt (2008) traz:

O discurso no institucionalismo discursivo ocorre de duas maneiras: discurso coordenativo entre indivíduos e grupos no centro do desenvolvimento de políticas que estão envolvidos em criar, elaborar e justificar a política, e o discurso comunicativo na apresentação, deliberação e legitimação das ideias da política para o público. 0 institucionalismo discursivo também explica o contexto no qual o discurso ocorre, com instituições sendo estruturas existentes que restringem atores e ideias, e construtos que são formados e adaptados pelos atores (p.303).

Como destaca Schmidt (2012), o discurso elucida as formas nas quais as armadilhas das ideias capturam os agentes. As ideias não flutuam livremente, pois elas precisam ser levadas pelos agentes. Como os interesses materiais dos atores não estão desconectados das ideias por eles veiculadas e defendidas, a comunicação, discussão, negociação, contestação e deliberação constituem os processos de interação discursiva (Schmidt, 2012) que permitem a construção da ação coletiva e, no caso das 
elites políticas, a formação de coalizões. Para isso, interessa ver quem fala, para quem, o que, onde e por que. Os agentes dos discursos coordenativos, em oposição ao discurso comunicativo direcionado para a sociedade de um modo geral, estão envolvidos na geração das ideias de políticas públicas e nos argumentos com diferentes graus de influência. São diferentes agrupamentos que se organizam para influenciar a geração, moldagem e adoção de políticas públicas (Schmidt, 2012).

Além disso, as questões relacionadas ao ambiente institucional como legislação tributária, infraestrutura, relações entre capital e trabalho, estabilidade no funcionamento das instituições com regras do jogo estáveis e estruturas de incentivo que inibem a inovação como estratégia de aumento dos lucros e de crescimento econômico constituem parte das condições implícitas.

A análise dos discursos dos parlamentares em torno de uma agenda de inovação também permite entender melhor a formação das preferências dos atores. De acordo com as contribuições do institucionalismo centradono ator (actor-centred institutionalism), há quatro elementos que ajudam a entender a formação de preferências (Treib, 2015). O primeiro se refere aos próprios interesses institucionais das organizações ou dos partidos como crescimento, força e poder (ainda que no caso brasileiro os partidos sejam fracos e as bancadas são estruturadas em função de grupos de interesse relacionados aos processos de lobby).

O segundo elemento guarda relação com as expectativas normativas em relação aos atores. No caso deste artigo, um aspecto chave é a expectativa de ser o partido de oposição e com uma visão de sociedade e de mundo diferente dos partidos da situação. O terceiro elemento tem a ver com a identidade dos atores. Um exemplo é a construção identitária como um partido mais ao centro ou mais à direita ou à esquerda no espectro ideológico. Por fim, o quarto elemento se refere à orientação da interação do ator. Ou seja, quais os interesses ele tem em mente quando se coloca em uma situação de decisão.

\section{MÉTODO}

Foram extraídos 521 discursos de senadores diretamente do site do Senado Federal e mais 430 discursos de deputados extraídos diretamente do site da Câmara dos Deputados. No caso da Câmara, a pesquisa foi efetuada com os termos "inovação" e "pesquisa e desenvolvimento", sendo efetuada uma divisão posterior em 14 categorias de análise, sendo elas: Certificação e Metrologia; Estímulo à Indústria de Base; Estímulo Interno (compras governamentais); Fomento a Alto Valor Agregado; Fomento a Exportações; Inovação Agro; Interiorização da Indústria e do Conhecimento; Investimento em Infraestrutura; Participação de micro e pequenas empresas; Participação do setor privado; Recursos Humanos; Setor Energético; Setores Estratégicos e, finalmente, a categoria Uso da Infraestrutura de Conhecimento. A pesquisa no site do Senado foi efetuada com os termos "inovação" e "pesquisa e 
desenvolvimento", sendo esses termos filtrados posteriormente em 10 categorias de análise de acordo com a natureza do discurso proferido. Tais categorias de análise, para o caso do Senado, foram as seguintes: Ciência e Tecnologia; Desenvolvimento Regional; Economia Nacional; Governo Federal; Política Científica e Tecnológica; Política Agrícola; Política de Desenvolvimento; Política Energética; Política Industrial e, finalmente, Telecomunicações.

Pelo fato dos sites da Câmara e do Senado dividirem os filtros de pesquisa de forma diferente, o presente autor também teve que efetuar a diferenciação, tentando aproximar ao máximo as categorias de análise das duas Casas legislativas. O período analisado foi de 10 anos, de 2008 a julho de 2018. Os trechos de discursos foram extraídos dos dois sites com base no nível comunicativo e coordenativo que trazem, de acordo com Schmidt (2008), além de uma análise da estrutura do argumento (Brun e Betz, 2016).

Os discursos foram separados em cada categoria de análise para posteriormente serem analisados pelo software de análise qualitativa NVivo versão 8. Os discursos foram rodados no software isoladamente (somente Câmara e somente Senado) e juntos, sendo analisadas as duas Casas ao mesmo tempo. Cada discurso foi tratado como um "nó" dentro do software, sendo efetuada a divisão em cada partido, de modo a possibilitar a extração do percentual da participação de cada categoria de análise no discurso de cada partido político. Somente os partidos com maior participação discursiva no tema "inovação" entraram na análise (partidos com pelo menos cinco discursos). Tais partidos foram: PT, PMDB, PCdoB, DEM, PSDB, PSB, PSC, PTB, PR, PDT e PPS.

A partir da análise com o NVivo versão 8 , foi possibilitada a coleta quantitativa da participação percentual de cada partido em cada categoria de análise, resultado que será mostrado na próxima parte do presente trabalho.

\section{FRAGMENTAÇÃO E CONVERGÊNCIAS NA AGENDA DE INOVAÇÃO}

Para uma primeira análise da fragmentação e convergências na agenda de inovação, são consideradas as frequências das codificações dos discursos nas categorias construídas a partir dos textos analisados. A análise tem início pelo Senado Federal, seguida pelo congresso e por uma comparação entre ambos. Na sequência, são apresentados excertos e análise dos principais partidos no congresso no período PT, PMDB como governo e PSDB e DEM como oposição.

No Senado, o PT teve o seu maior percentual quando se tratou da categoria de análise "Governo Federal" em relação aos temas vinculados à inovação. Isso pode ser devido ao período analisado, onde o PT esteve no governo a maior parte do tempo (2008-2016) e seus parlamentares trataram de assuntos mais voltados à inovação no domínio do próprio governo. A segunda categoria mais frequente dos discursos na 
Câmara foi política de ciência e tecnologia (14,46\%), seguida pela economia nacional $(12,83 \%)$ e política industrial (9,38\%) (Tabela 1$)$. Em relação ao PMDB como principal partido da base do governo, a 'economia nacional' apresenta a maior frequência com 19,47\%. O governo federal está em segundo com 17,27\% e, em terceiro, a política industrial com $12,97 \%$. Um dos pontos em comum dos dois partidos foram as compras governamentais como um tipo de política industrial. As compras públicas foram destacadas como instrumento para favorecer o desenvolvimento do software nacional.

No Senado, o PMDB apresentou a maior quantidade de discursos, com 107 analisados. Dentre esses discursos, a maior parte tratou da categoria "Economia Nacional" no âmbito da inovação, seguido pela categoria "Governo Federal", com mais de $17 \%$ de participação. O PP também seguiu o mesmo padrão, com as mesmas duas categorias em primeiro e segundo lugar em participação. O PTB também teve sua maior participação na categoria "Economia Nacional", com 47,66\%, seguido pela categoria "Política científica e tecnológica”, com 11,79\%.

Um exemplo foi a Lei 12.349 de 2014 que institui a margem de preferência de até $25 \%$ em produtos nos processos de licitação paraprodutos manufaturados e serviços nacionais que atendam às normas técnicas brasileiras. No entanto, não há clareza na escolha dos setores tendo em vista que a indústria têxtil e de calçados é colocada juntamente com complexo de saúde, defesa, e tecnologia da informação e comunicação. Em relação aos critérios para a definição das margens, o critério da inovação não é priorizado, pois ele aparece juntamente com geração de emprego e renda e desenvolvimento.

Um outro elemento convergente entre os dois partidos em relação à política industrial foi o papel do BNDES no financiamento ao desenvolvimento industrial. Parlamentares do PMDB defenderam a concessão de subvenção ao BNDES para dar continuidade à política de apoio à indústria de bens de capital e de bens de consumo para exportação e inovação tecnológica do artigo $1^{\circ}$ da Lei n 12.096, de 2009. A ênfase na subvenção para as operações de crédito do BNDES é também vista como medidaanti-cíclica para a crise global de 2008, além de serem operações de crédito destinadas a apoiar as empresas brasileiras em setores estratégicos ligados à inovação tecnológica, à produção de bens de capital, como também ao setor de petróleo, com destaque para os investimentos da Petrobras.

Para o PSDB, como principal partido de oposição, as categorias mais frequentes foram 'Governo Federal' com 35\% seguido por desenvolvimento regional (15,41\%), economia nacional (10,42\%) e política industrial (10,31\%). Já o DEM, como segundo principal partido de oposição, não converge com o PSDB. As categorias mais frequentes de codificação foram a 'política de ciência e tecnologia' (39,29\%), a 'política de desenvolvimento' (27\%) e o'desenvolvimento regional' (14,71\%) (Tabela 1). 


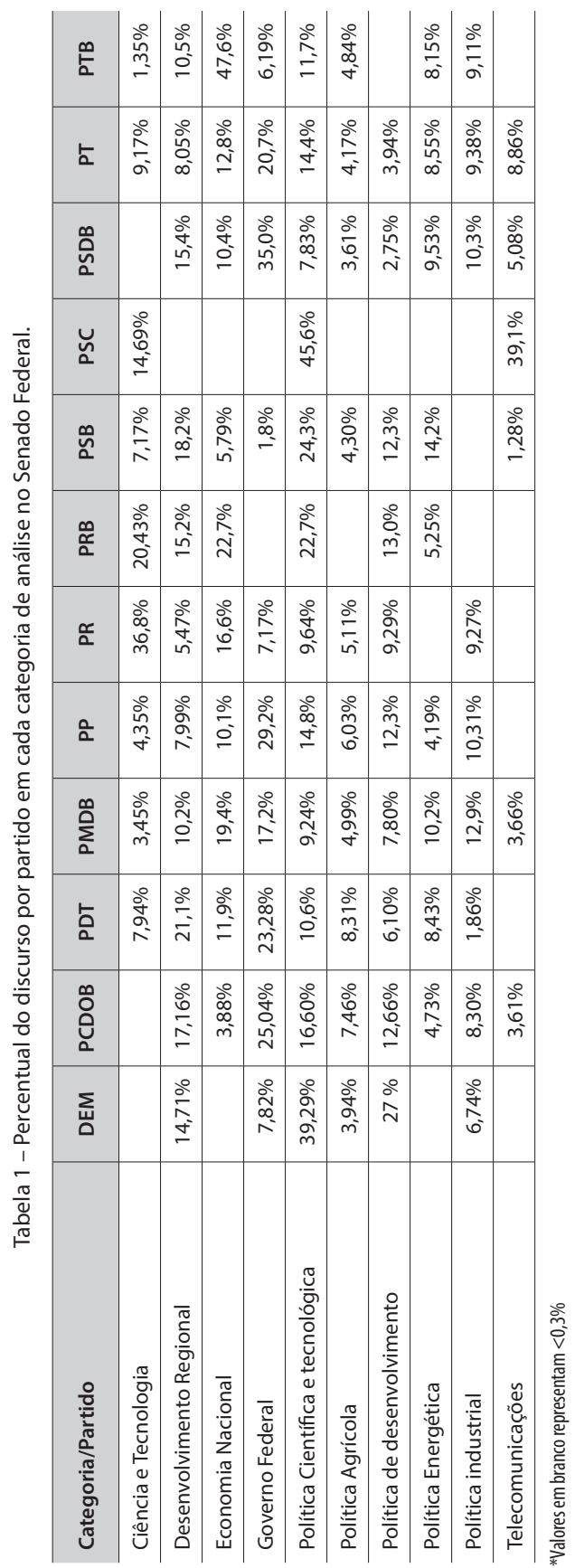


Em relação à política industrial, há um destaque para as compras públicas com destaque o regime diferenciado de compras. Há consenso de que a Lei no 8.666 é bastante limitada para a utilização de compras públicas como instrumento de apoio à inovação. Na cooperação entre universidade e empresas, houve um destaque para uma legislação mais flexível para as fundações de apoio às universidades federais. Em particular, o financiamento às atividades de gestão operacional nos projetos de cooperação entre universidades, empresas e governo. Também destacam o uso adequado do poder de compra do Estado como uma medida fundamental para o ganho de competitividade, assim como a redução do déficit e o aumento das exportações no setor de saúde brasileiro. Essa estratégia evidencia, em um contexto internacional, a qualidade do produto brasileiro e incentiva sua aquisição por outros países.

Para o PSDB, o financiamento ao desenvolvimento industrial com a mudança de regras no BNDES foi criticado pela improvisação. Houve uma especial crítica à desoneração pontual. É citado o exemplo do Eike Batista em que as empresas do grupo tiveram uma forte desvalorização de mercado em 2013 e o fato do grupo ter dívidas bastante elevadas com o BNDES. É citado um projeto de que o BNDES deva destinar $40 \%$ do seu financiamento para pequenas e microempresas. No entanto, de acordo com o Livro Verde (BNDES, 2017) o percentual de desembolso para as Micro, Pequenas e Médias Empresas (MPMES) variou de 40,7\% em 2001 para 62\%. O percentual atingiu seu pico mais baixo em 2009 com as medidas anti-cíclicas com 28,2\% destinados às MPMES (Tabela 1).

Como pode ser visto na Figura 1, a maior convergência na codificação é vista em setores estratégicos com destaque para os investimentos em energia e a cadeia de petróleo e gás, com maior frequência das falas de senadores do PMDB nesta categoria. Em um dos excertos, os eixos estratégicos apontados foram: agropecuária e agroindústria, energias, petróleo e gás complexo da saúde, complexo aeroespacial e de defesa, tecnologia da Informação e comunicação e sustentabilidade ambiental. Trata-se de uma convergência entre os principais partidos da situação (PMDB e PT) e da oposição (PSDB e DEM). Para a infraestrutura de conhecimento, nota-se uma convergência entre o PSDB e o PT quanto ao tamanho da codificação. No entanto, as falas de senadores do PSDB focam no estado de São Paulo e nos recursos para a pesquisa das universidades estaduais e para a Fundação de Pesquisa do Estado de São Paulo (FAPESP). No caso das falas de senadores do PT, houve destaque para os Institutos Federais e para o estado do Amazonas. Também houve menção a uma agenda de desenvolvimento da Associação Nacional dos Dirigentes das Instituições Federais de Ensino Superior (ANDIFES).

Para a participação do setor privado em P\&D, um senador do PSDB destacou a relevância da 'Lei do Bem' que facilita a interação entre as universidades e empresas e, especialmente, os incentivos fiscais para investimentos em pesquisa e desenvolvimento. No caso dos senadores do PMDB, houve destaque para o desenvolvimento de 
instrumentos ágeis de apoio à inovação. As falas resultaram de uma apresentação do presidente da FINEP à época, Glauco Arbix, e de um representante da CNI, Rafael Lucchesi. Além da habitual constatação de que as empresas privadas investem pouco em inovação no país, foi destacada a importância da criação da Empresa Brasileira de Pesquisa e Inovação Industrial (EMBRAPII). A menção à EMBRAPII faz referência ao início da sua atuação com o Instituto Tecnológico de São Paulo, com o SENAI e um centro de automação industrial em São Paulo.

O PT registrou uma participação maior do que os outros partidos na categoria investimentos em infraestrutura, seguido pelo DEM como partido de oposição. No caso do PT, as falas foram relacionadas com as Parcerias Público Privadas (PPPs), a integração ferroviária com os países andinos e o Programa Revitaliza do BNDES. Em uma das falas, os investimentos públicos e privados em infraestrutura são vistos como uma forma de superação da crise econômica. Citando um relatório da CNI, um dos senadores do PMDB destaca a necessidade de o governo reduzir os gastos correntes para privilegiar os investimentos públicos em infraestrutura.

No caso do DEM, um senador aponta a demora dos planos de investimentos em infraestrutura saírem do papel em todo o primeiro mandato de Lula. O senador chama atenção que apenas em 2007 houve um programa de recuperação e implantação de infraestrutura. Há uma crítica de que do montante de recursos anunciados no Programa de Aceleração do Crescimento (PAC) de R\$ 557 bilhões, cinquenta bilhões foram do governo federal, sendo o restante de empresas estatais e de empresas privadas. A fala do senador do PSDB codificada foi mais específica sobre a atração de empresas de tecnologia para a cidade de Campina Grande e de João Pessoa.

Na Câmara, o PT teve sua maior participação na categoria de análise "Uso da infraestrutura de conhecimento" (20,20\%), sendo o discurso mais voltado a questões relacionadas às universidades federais, às escolas técnicas e similares. O segundo maior enfoque do PT na Câmara foi a categoria "Investimento em Infraestrutura" (15,56\%). O mesmo ocorreu com o PSDB, que teve uma participação de $37,64 \%$ e $17,89 \%$ respectivamente. Os discursos do Deputado Izalci (PSDB-DF) tiveram grande influência no aumento percentual da participação na categoria de análise "Uso da Infraestrutura de Conhecimento", pois grande parte dos seus discursos foram voltados à questão da inovação e desburocratização das universidades. O PSB teve sua maior participação na categoria de análise “Setor Energético", com 30,26\% seguido pela sua participação na categoria “Uso da Infraestrutura de Conhecimento, com 14,66\%.

No caso do PCdoB, no Senado, o partido teve uma participação maior na discussão tratando da inovação no tema "Governo Federal", com 25,04\%, seguido pela categoria "Política Científica e Tecnológica", com 16,6\%. Pelo fato do PCdoB ter estado alinhado com o PT durante toda a trajetória do governo Lula e Dilma, isso pode indicar a razão pela qual o percentual dessa categoria de análise foi predominante (no caso do PT, $20,71 \%$, sendo também predominante em relação às outras categorias). Na Câmara, o PCdoB teve uma participação menor na discussão, tendo participação em apenas 
5 das 14 categorias de análise, sendo que o maior percentual foi para o "uso da infraestrutura de conhecimento". Todos os partidos analisados, exceto o PSC, tiveram uma participação de mais de $10 \%$ nessa categoria.

O DEM tratou com maior intensidade do tema "Política Científica e Tecnológica", com 39,29\%, seguido pelo tema Política de desenvolvimento, com 27,02\%. O PR tratou com maior intensidade do tema "Ciência e Tecnologia", com 36,82\%. O PSC, apesar de ter uma participação em 3 categorias de análise (C\&T, Política científica e tecnológica e Telecomunicações), não teve uma quantidade muito significativa de discursos (apenas 6) para se poder analisar um posicionamento do partido com maior profundidade. Os partidos citados tiveram uma participação menos ativa na discussão sobre inovação, com um menor número de discursos captados.

Já na Câmara, o DEM teve um percentual maior na categoria "Investimento em Infraestrutura" (21,87\%), com $15,16 \%$ para a categoria "Uso da Infraestrutura de conhecimento" logo em seguida. O PR teve mais da metade dos seus discursos (53\%) direcionados ao "uso da infraestrutura de conhecimento", seguido por 15,6\% na categoria Investimento em infraestrutura. O PSC teve participação em mais categorias de análise na Câmara do que no Senado, sendo a sua categoria de análise mais visível "Fomento a Exportações", com 39,64\%, indicando um enfoque completamente diferente dos outros partidos analisados até o momento. Para o mesmo partido, a categoria de análise "investimento em infraestrutura" ficou com 18,65\%, o que indica que os 3 partidos analisados têm dado importância ao tema.

Figura 1 - Distribuição de frequência do número de palavras dos excertos codificados dos principais partidos de oposição e de situação no período de 2008-2018.

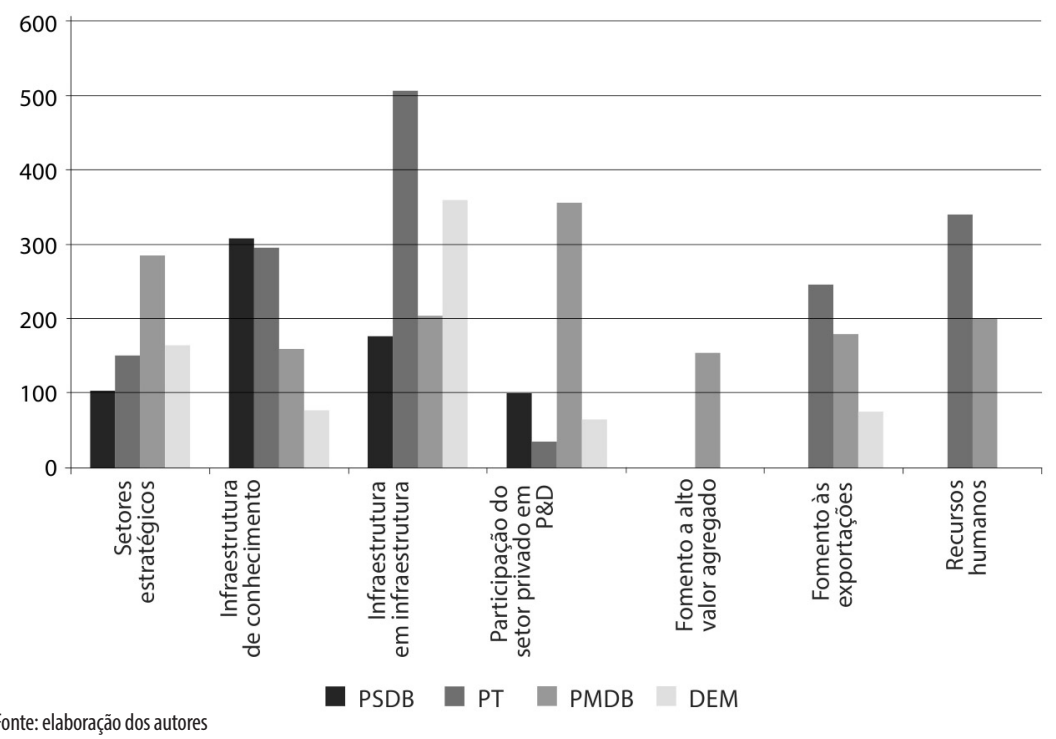


Na Câmara, o PMDB tratou do tema "Setor Energético" com maior intensidade $(24,41 \%)$, e do tema "uso da infraestrutura de conhecimento" logo depois, com $18 \%$ dos seus discursos proferidos nesse sentido. O PP também manteve o mesmo padrão do PMDB na Câmara, com 28\% e 24\%. O PTB também tratou com maior intensidade do tema "Setor Energético", o que indica uma tendência clara desses partidos a tratarem do assunto. No caso do PTB na Câmara, poucos discursos sobre o tema inovação foram analisados, o que ajudou o percentual da categoria de análise "Setor Energético" a ficar com mais de $60 \%$ da quantidade de discursos.

Outros partidos com menor representação no congresso também tiveram participação na discussão, sendo esses partidos o PSOL, PTN, PV, PROS, REDE e Solidariedade. Pelo fato de tais partidos terem proferido menos discursos, não há como retirar com confiabilidade mínima um posicionamento claro a respeito dos temas atrelados à inovação. Por essa razão, esses partidos foram deixados de fora da análise feita com os outros partidos com maior representação.

No Senado, apesar do número bem menor de parlamentares, houve uma solidez maior na discussão sobre a inovação em comparação à Câmara. Os partidos com maior representação tiveram uma solidez participativa na análise, tratando de todos ou quase todos os temas relacionados à inovação. $O$ destaque no Senado vai para o PT, PMDB, PSDB e PP, que tiveram uma grande quantidade de discursos $(120,107,47$, e 40, respectivamente). Na Câmara, os mesmos partidos tiveram a maior participação discursiva, exceto pelo PSB que entrou no lugar do PP. A análise ficou com 88 discursos para o PT, 76 para o PSDB, 36 para o PMDB e 36 para o PSB.

É importante ressaltar que, a partir do ano de 2014, a quantidade de discursos a respeito de inovação diminuiu bruscamente, tendo apenas 107 discursos na Câmara de 2014 até 2018 (em comparação com 320 de 2008 ao final de 2013), e no caso do Senado, foram 360 discursos de 2008 até o final de 2013 contra apenas 160 discursos de 2014 a 2018. O processo de impeachment e a grave crise econômica a partir do período de 2014, as duas Casas deixaram de tratar sobre inovação em detrimento de temas relacionados às crises política e econômica. Pode-se pensar, portanto, na influência que esses eventos podem ter sobre a discussão de temas importantes no Legislativo, o que pode trazer um retrocesso à atividade de estímulo à inovação do país.

A fim de deixar mais clara a visualização das convergências e das fragmentações em relação aos temas ligados à agenda de inovação, a Figura $\mathbf{2}$ apresenta um mapa mental que mostra a maior intensidade dos temas em geral e por partido político (quanto maior o balão da figura, maior é a quantidade de discursos relacionados com o tema ou quantidade de discursos do partido).

Quando os balões estão colocados em lados opostos, isto indica divergências no posicionamento. Considerando os principais partidos do governo à época, PT e PMDB, a convergência entre os dois partidos no Senado somente ocorreu nos temas da política industrial e da infraestrutura. Em relação aos principais partidos de oposição, 


\begin{tabular}{|c|c|c|c|c|c|c|c|c|c|c|c|c|c|c|}
\hline$\stackrel{\infty}{\frac{0}{\alpha}}$ & & & & & & & & & & & & 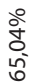 & \begin{tabular}{l}
$\stackrel{0}{ }$ \\
$\infty$ \\
$\infty$ \\
\multirow{\leftarrow}{*}{}
\end{tabular} & 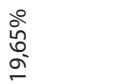 \\
\hline เ & 亮 & $\stackrel{\circ}{\stackrel{\circ}{m}}$ & $\begin{array}{l}\text { 今े } \\
\text { ڤึ } \\
0\end{array}$ & $\underset{\infty}{\stackrel{0}{\grave{\infty}}}$ & 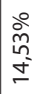 & 亭 & 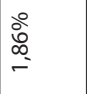 & 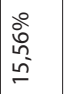 & $\frac{\stackrel{\circ}{\check{\sigma}}}{\stackrel{\circ}{\sigma}}$ & 宂 & $\frac{\text { ì }}{\frac{0}{0}}$ & $\begin{array}{l}\text { 今े } \\
\text { ô. } \\
\text { ․ }\end{array}$ & $\begin{array}{l}\text { ○े } \\
\text { مू } \\
\text { ণ }\end{array}$ & $\begin{array}{l}\text { 今े } \\
\text { ஸ̃ } \\
\text { ஸे }\end{array}$ \\
\hline 气ิ & 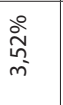 & & 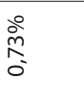 & 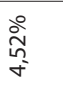 & $\frac{\stackrel{2}{\hat{N}}}{\hat{\sigma}^{\circ}}$ & $\begin{array}{l}\stackrel{\circ}{\grave{h}} \\
\stackrel{\infty}{-} \\
\stackrel{-}{-}\end{array}$ & & $\begin{array}{l}\stackrel{0}{2} \\
\text { ò } \\
\stackrel{-}{\perp} \\
-\end{array}$ & $\begin{array}{l}\text { ò } \\
\text { ò } \\
\text { in }\end{array}$ & $\frac{\stackrel{0}{c}}{\bar{c}}$ & 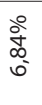 & $\begin{array}{l}\text { 。े } \\
\text { ᄋ̆ } \\
\text { ᄋ }\end{array}$ & & 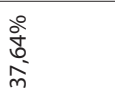 \\
\hline$\stackrel{u}{\simeq}$ & & & & $\begin{array}{l}\text { ○̊ } \\
\text { مू } \\
\text { ᄋ }\end{array}$ & $\begin{array}{l}\text { ờ } \\
\text { ర్ } \\
\text { ò }\end{array}$ & & & $\begin{array}{l}\stackrel{0}{\circ} \\
\hat{0} \\
\infty \\
\infty \\
\infty\end{array}$ & & & & $\begin{array}{l}\stackrel{0}{\circ} \\
\text { ôn } \\
\underline{0} \\
\underline{0}\end{array}$ & $\begin{array}{l}\text { oे } \\
\text { ò } \\
\text { m- }\end{array}$ & \\
\hline 气ิ & $\begin{array}{l}\stackrel{0}{0} \\
\vdots \\
\infty \\
\infty\end{array}$ & & 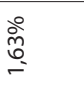 & 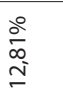 & & $\begin{array}{l}\text { ○े } \\
\text { in } \\
\text { in }\end{array}$ & & & $\begin{array}{l}0 \\
\text { oे } \\
0 \\
0\end{array}$ & $\frac{\stackrel{2}{\Sigma}}{\grave{i}}$ & 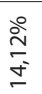 & $\begin{array}{l}\text { ¿ें } \\
\text { సै } \\
\text { ठे }\end{array}$ & $\begin{array}{l}\stackrel{\circ}{\circ} \\
\text { N్} \\
\stackrel{n}{n}\end{array}$ & 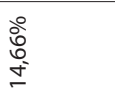 \\
\hline$\stackrel{\frac{\pi}{\alpha}}{2}$ & $\begin{array}{l}\text { oे } \\
\text { o̊ } \\
\text { ì }\end{array}$ & & & $\begin{array}{l}\stackrel{\circ}{\stackrel{+}{+}} \\
\stackrel{+}{*}\end{array}$ & & & \&̊ㅇ & $\begin{array}{l}\text { o̊ } \\
\text { ơ } \\
\text { in }\end{array}$ & $\stackrel{\circ}{\stackrel{\circ}{\stackrel{2}{*}}}$ & 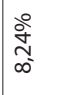 & 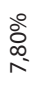 & $\frac{\circ}{\stackrel{f}{\mp}}$ & & $\begin{array}{l}\text { 今े } \\
\text { ठ̊. } \\
\text { ก̀ }\end{array}$ \\
\hline$\check{a}$ & $\begin{array}{l}\text { 今े } \\
\text { ठे } \\
\text { N }\end{array}$ & $\begin{array}{l}\text { Oें } \\
\text { m. } \\
\text { v }\end{array}$ & & $\begin{array}{l}\text { 今े } \\
\text { ळे } \\
\text { f }\end{array}$ & $\begin{array}{l}\stackrel{0}{\circ} \\
\infty \\
\infty \\
\stackrel{ }{\simeq}\end{array}$ & & & 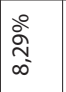 & 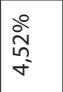 & $\begin{array}{l}\stackrel{\circ}{O} \\
\stackrel{+}{+} \\
\stackrel{+}{*}\end{array}$ & & $\begin{array}{l}\text { 今े } \\
\text { oे } \\
\text { ڤે }\end{array}$ & $\begin{array}{l}\text { oे } \\
\infty \\
\sigma \\
\sigma\end{array}$ & 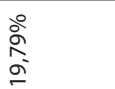 \\
\hline$\stackrel{0}{2}$ & & & & $\underset{\substack{\stackrel{0}{0} \\
\stackrel{\infty}{\wedge}}}{ }$ & 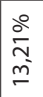 & 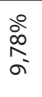 & $\begin{array}{l}\stackrel{\circ}{\infty} \\
\stackrel{\infty}{\infty} \\
-\end{array}$ & $\frac{\stackrel{\circ}{\frac{1}{2}}}{\cos }$ & & $\frac{\grave{2}}{\dot{m}}$ & & $\begin{array}{l}\stackrel{\circ}{\infty} \\
\stackrel{\infty}{\wedge} \\
\stackrel{\infty}{\sim}\end{array}$ & & 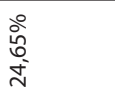 \\
\hline$\sum_{a}^{\infty}$ & & $\begin{array}{l}\text { 今े } \\
\stackrel{+}{+} \\
\stackrel{+}{*}\end{array}$ & 犬̊ & $\stackrel{\stackrel{\circ}{\stackrel{\circ}{n}}}{\text { m }}$ & 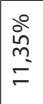 & $\begin{array}{l}\text { वे } \\
\infty \\
\infty^{\circ} \\
\infty^{\circ}\end{array}$ & & $\begin{array}{l}\stackrel{\circ}{0} \\
\hat{N} \\
\infty \\
\infty\end{array}$ & $\begin{array}{l}\stackrel{\circ}{\infty} \\
\stackrel{\sim}{\infty} \\
\text { m }\end{array}$ & $\begin{array}{l}0 \\
8 \\
0 \\
0\end{array}$ & & $\begin{array}{l}\stackrel{\circ}{\circ} \\
\stackrel{\sim}{d}\end{array}$ & $\begin{array}{l}\stackrel{\circ}{\stackrel{9}{*}} \\
\text { in }\end{array}$ & 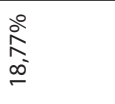 \\
\hline$\stackrel{5}{2}$ & & & & & & 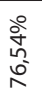 & & & & & & & & 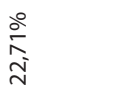 \\
\hline 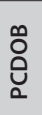 & 导 & & & 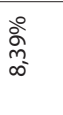 & $\begin{array}{l}\stackrel{0}{0} \\
\hat{\tilde{O}} \\
\infty \\
\infty\end{array}$ & & & & & & & $\begin{array}{l}\text { مे } \\
\text { ले } \\
\text { సે }\end{array}$ & & $\begin{array}{l}\text { ○े } \\
\text { ơ } \\
\text { ळे }\end{array}$ \\
\hline$\sum_{\text {u }}$ & & & & \begin{tabular}{l} 
ஓ̊ \\
$\hat{0}$ \\
\multirow{+}{*}{}
\end{tabular} & 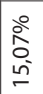 & $\begin{array}{l}\stackrel{\circ}{c} \\
\stackrel{m}{\sim} \\
\end{array}$ & & $\begin{array}{l}\stackrel{0}{N} \\
\infty \\
\grave{N} \\
\bar{n}\end{array}$ & $\begin{array}{l}\text { oे } \\
\text { ஸे } \\
\alpha\end{array}$ & & & $\begin{array}{l}\text { 今े } \\
\text { ปे }\end{array}$ & & $\begin{array}{l}\stackrel{8}{\circ} \\
\frac{0}{n}\end{array}$ \\
\hline 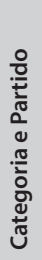 & 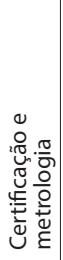 & 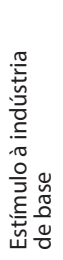 & 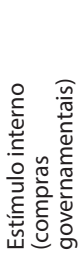 & 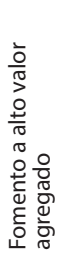 & 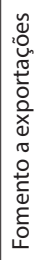 & 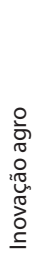 & 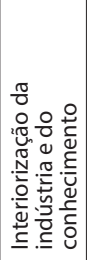 & 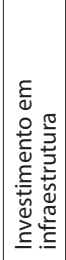 & 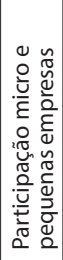 & 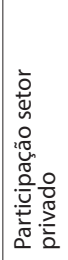 & 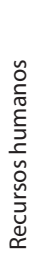 & 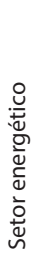 & 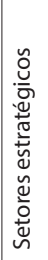 & 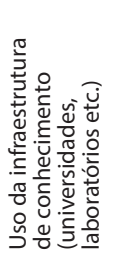 \\
\hline
\end{tabular}


PSDB e DEM, não foi identificada convergência nestes temas no âmbito do Senado. Nos discursos da Câmara Federal, não houve convergência entre PT e PMDB e uma convergência entre o PSDB e DEM no tema da infraestrutura.

Figura 2 - Mapa mental dos temas abordados na Câmara e Senado*.
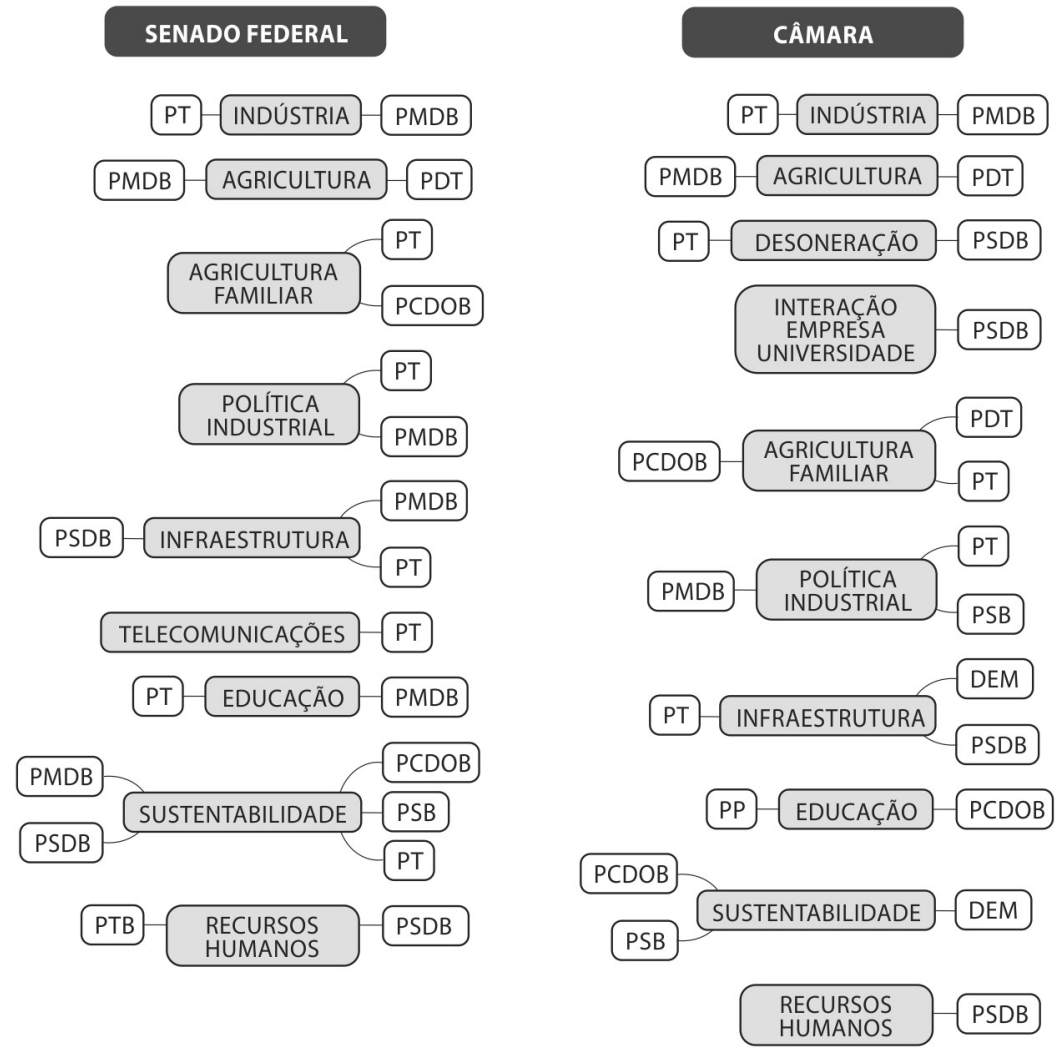

Fonte: Produção dos autores com uso do programa online https://www.mindmup.com/

* Quanto maiores os "balões" de cada partido, maior a quantidade de discursos relacionados ao tema. Ao contrário das tabelas, onde foram analisados os conteúdos dos discursos, a figura abaixo representa a quantidade de trechos por partido e por tema de uma forma mais visual. Balões posicionados em direções opostas trazem uma relação de oposição entre os partidos, enquanto os posicionados no mesmo lado trazem uma ideia de coalizão e cooperação entre os partidos.

Para acrescentar mais dados a esta discussão, o presente autor traz uma análise de cluster feita pelo software NVivo 10. A Figura 3 mostra a proximidade entre os discursos de cada partido. Ou seja, quanto mais próximos os partidos na figura, maior a correlação entre os seus discursos. As duas Casas legislativas foram analisadas separadamente de modo a mostrar com maior precisão as principais aproximações partidárias em cada uma delas. 
Figura 3 - Aproximação discursiva por similaridade de palavras dos partidos na Câmara (à esquerda) e no Senado (à direita).

Nós em cluster por similaridade de palavra

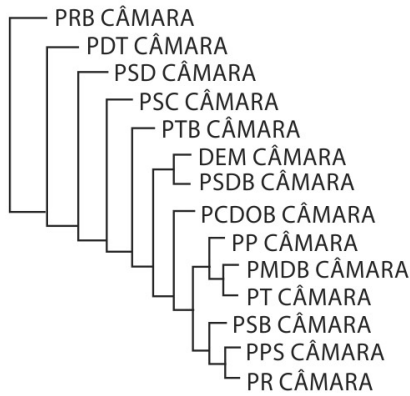

Nós em cluster por similaridade de palavra

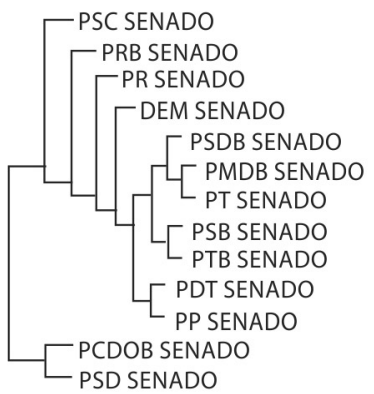

Fonte: Elaboração do próprio autor, com o uso do software NVivo 10

Nota-se que há uma aproximação grande entre os discursos do PMDB e do PT no grau de similaridade nas palavras, do DEM e do PSDB, do PPS e do PR e um distanciamento correlativo de partidos como o PDT, PSD, PSC e PRB em relação aos partidos com maior representação no congresso. A aproximação entre PMDB e PT, apesar das diferenças ideológicas, pode se dever à aliança formada entre os dois partidos. Com relação ao PSDB e o DEM, tal aproximação pode ter sido devida à oposição que os dois partidos fizeram ao PT e ao PMDB durante os governos Lula e Dilma. Nota-se, pela mesma figura, que o PSB se aproximou mais do PPS e do PR, sendo que o PR é um partido ideologicamente distante do PSB e do próprio PPS (em teoria). Entretanto, a análise de correlação feita pelo software ainda está sujeita a vieses por não diferenciar propriamente o tom de oposição nos discursos proferidos, sendo que as mesmas palavras podem ser usadas para defender ou atacar um assunto. Apesar disso, nota-se que a aproximação feita pelo software no caso da Câmara parece razoável, uma vez que os principais partidos foram organizados de uma forma que retrata a realidade das coligações dentro do Congresso.

Já no caso da figura do Senado, houve uma aproximação discursiva maior do PSDB em relação ao PMDB e ao PT, mas isso pode ter sido devido ao viés citado anteriormente. O PMDB e o PT aparecem novamente no mesmo "ramo", sendo que o DEM já aparece um pouco mais distanciado do PSDB em relação ao que foi analisado no clusterda Câmara. Os partidos que apareceram distanciados no caso da Câmara também apareceram mais distanciados no caso do Senado (PRB, PSC e PR). Percebese uma aproximação discursiva entre o PCdoB e o PSD. Entretanto, como o PSD teve uma quantidade pequena de discursos analisados, isso pode ter afetado de forma a enviesar essa parte da análise.

É importante trazer, também, a informação de que o PPS teve relevância discursiva na Câmara, mas não teve relevância no Senado, e que o PCdoB teve uma aproximação 
discursiva maior do PT e do PMDB (seus aliados na maior parte do período analisado) na Câmara do que no Senado. Isso pode se dever tanto a uma falta de alinhamento discursivo entre os parlamentares de um mesmo partido na Câmara e no Senado quanto à diferença do tratamento do mesmo tema em uma Casa e em outra.

Todos os setores ideológicos tiveram participação nos debates sobre inovação. Entretanto, percebe-se que há algumas deficiências notadas com maior evidência nos discursos. No caso do PCdoB, o partido teve grandes defasagens, tendo participação apenas em cinco das catorze categorias analisadas na Câmara, ao contrário do Senado, onde teve uma participação bem mais expressiva. Nesta última Casa, o PCdoB não teve participação apenas na categoria "ciência e tecnologia", mantendo percentuais de participação discursiva relativamente equilibrados nas categorias de análise restantes.

Na Câmara, o mesmo resultado foi percebido, juntamente com a deficiência encontrada na categoria "participação do setor privado". Tal fato pode ser devido, primeiro, à presença maior de deputados e senadores de outros partidos na bancada ruralista, o que pode diminuir a influência discursiva de partidos como o PT, PSDB e PDT no tema, e quanto à participação do setor privado, tal deficiência pode se dever à importância dada pelos partidos ditos progressistas ao papel do Estado na economia, no desenvolvimento e na inovação.

O PMDB, PP e o PTB tiveram sua maior deficiência, na Câmara, na categoria "certificação e metrologia", e no Senado na categoria "ciência e tecnologia". Isso pode denotar um distanciamento desses partidos de uma discussão ideológica sobre a inovação. O PTB não teve discursos voltados à "política de desenvolvimento", o que distancia os partidos da discussão, apesar da presença discursiva maciça do PMDB em outros temas.

O DEM, PR e o PSC tiveram mais deficiências em relação aos outros partidos mais à esquerda, mas as duas mais notáveis, no Senado, foram relacionadas às categorias "Economia Nacional" "Política Energética". Na Câmara, esses partidos também tiveram uma defasagem de discursos quanto à participação do setor privado e recursos humanos. Um "desconto" que se pode dar a esses partidos é o seu número menor de parlamentares, o que também ocorre com o PCdoB. Essa defasagem no número de parlamentares não ocorre com o PMDB, PT, PP e PR, por exemplo, o que também pode ter ajudado a "preencher" a totalidade das discussões por parte desses partidos.

As nuvens de palavras dos excertos codificados permitem verificar quais foram os vocábulos principais relacionados com os temas da inovação nos dois principais partidos da situação (PT e PMDB) e da oposição (PSDB e DEM). Como mostra a Figura 4, o PSDB esteve mais voltado para universidades e empresas com o tema da cooperação entre universidades e empresas e a maior articulação entre pesquisa básica e a pesquisa aplicada. A palavra 'indústria'não está entre as principais como pode ser visto. As palavras 'tecnologia', 'inovação', 'educação', 'pesquisas' e 'infraestrutura' aparecem na mesma intensidade. 
Figura 4 - PSDB Inovação e Tecnologia na Câmara

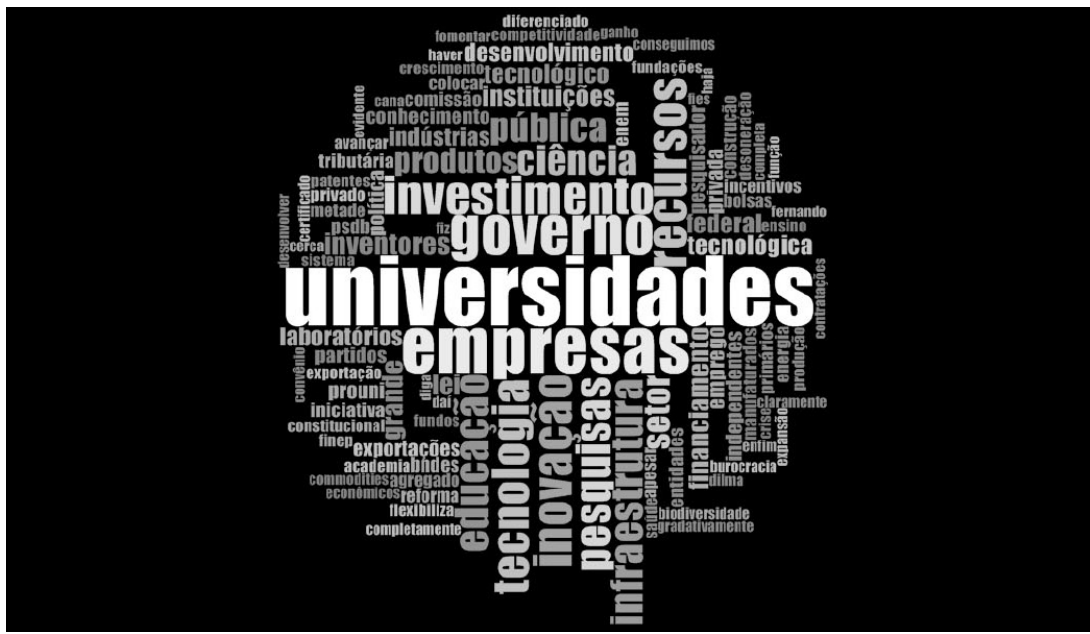

Fonte: Elaboração do próprio autor, com o uso do software NVivo 10

A Figura 5 mostra uma centralidade ainda maior da empresa, mas associada com governo em geral. As palavras 'tecnologia' e 'inovação' são menos importantes do 'recursos', 'infraestrutura' e 'agronegócio'. No entanto, a palavra 'indústria' aparece com o mesmo peso de 'tecnologia' e 'inovação'. Os principais vocábulos da Figura 5 não estão mais próximos do campo semântico da inovação.

Figura 5 - DEM Inovação e Tecnologia na Câmara

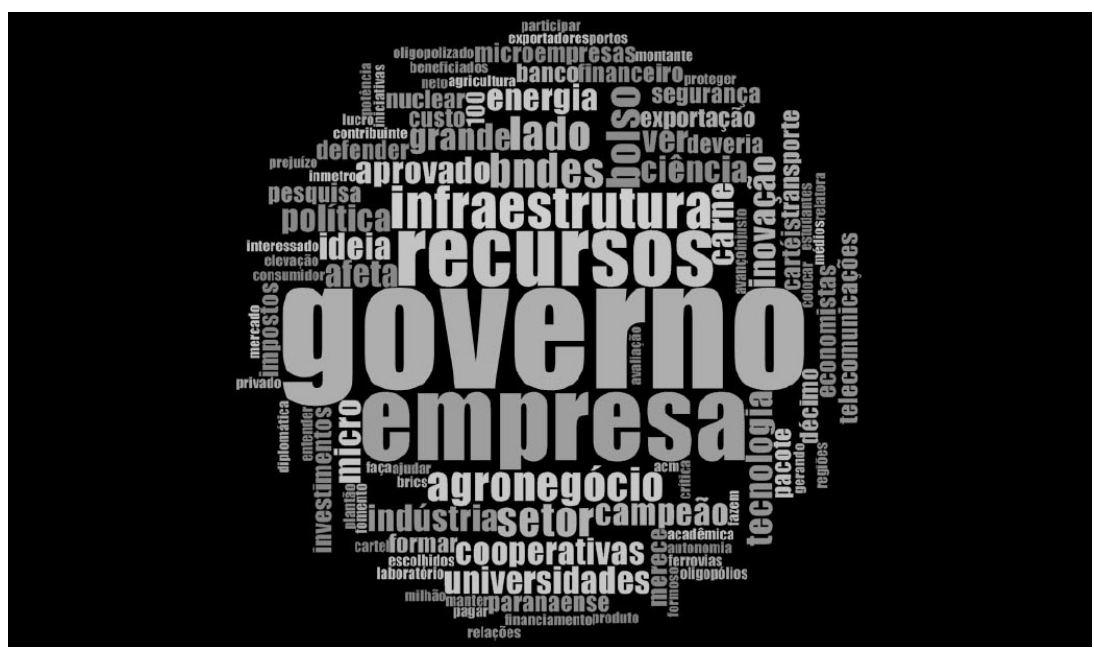

Fonte: Elaboração do próprio autor, com o uso do software NVivo 10 
No do PT, a Figura 6 revela uma distribuição mais equilibrada com destaque para as palavras 'indústria' e 'inovação'. Chama atenção também a palavra 'desenvolvimento' que não aparece como uma palavra central nas figuras anteriores. Na sequencia, seguem palavras que estão relacionadas com o campo semântico da inovação como 'tecnologia', 'pesquisas,' 'empresas' e 'universidades'.

Figura 6 - PT Inovação e Tecnologia na Câmara

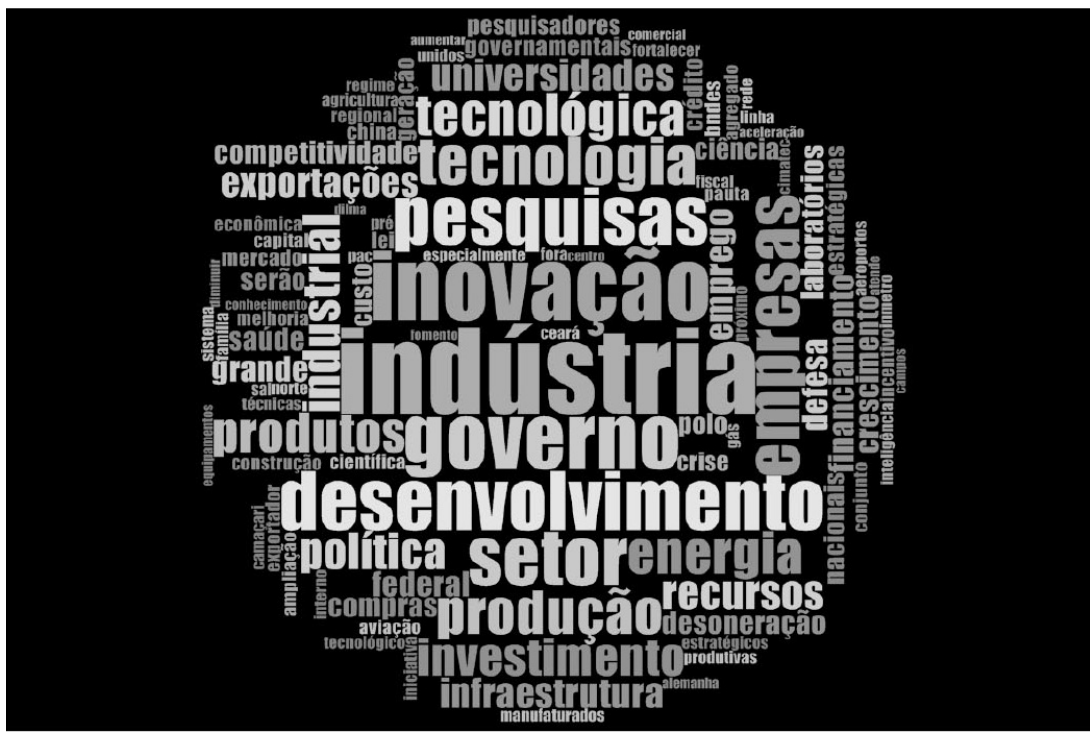

Fonte: Elaboração do próprio autor, com o uso do software NVivo 10

Na Figura 7, a nuvem de palavras do PMDB revela maior proximidade com o PT. Neste sentido, as figuras revelam uma convergência em torno de palavras como 'desenvolvimento', 'inovação', 'empresas', com um peso maior para a 'energia' e para a palavra 'universidade'. Considerando as quatro figuras, pode-se afirmar que o DEM apresenta maior distância em relação à agenda da inovação. 
Figura 7 - PMDB Inovação e Tecnologia na Câmara

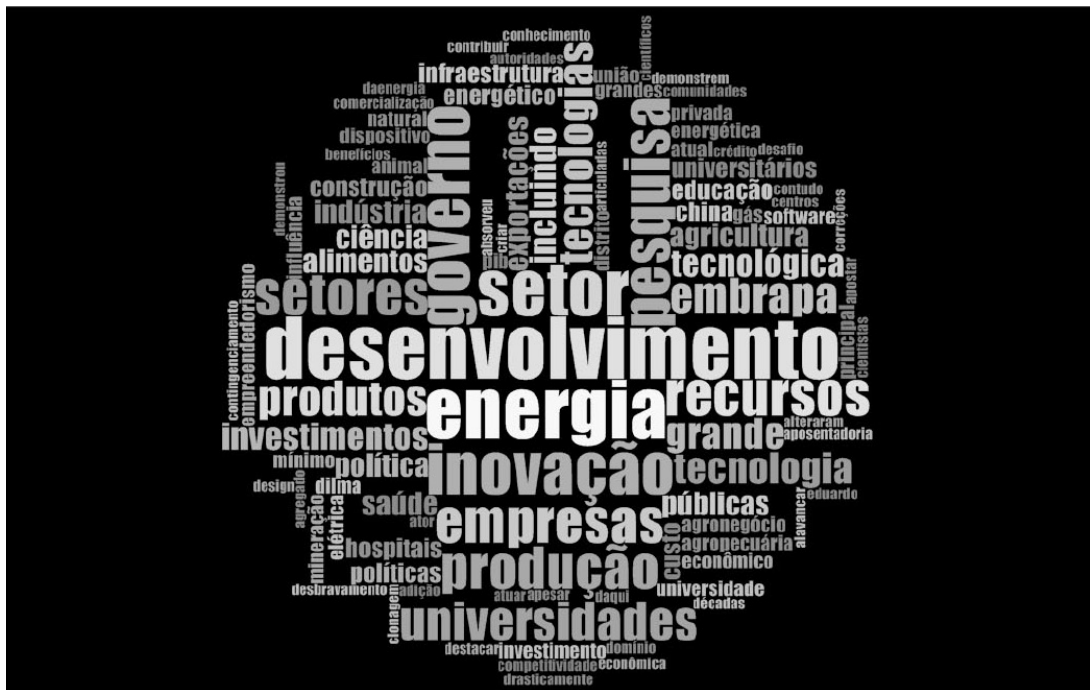

Fonte: Elaboração do próprio autor, com o uso do software NVivo 10

\section{CONCLUSÃO}

Como já foi dito anteriormente, o Brasil passou por um processo de instabilidade e ruptura institucional no governo Dilma, onde os temas centrais à discussão sobre inovação foram deixados em segundo plano para dar espaço às discussões sobre o impeachment. Tal fato limitou a análise a partir do ano de 2014, ano eleitoral, onde tais processos e discussões tiveram início. $O$ número de discursos diminuiu significativamente, o que pode apontar uma fragilidade da discussão, ao menos no Congresso Nacional. A divisão por partidos permitiu um entendimento mais objetivo de como os partidos encaram a inovação ao longo de todo o espectro ideológico. O período analisado (10 anos) também permitiu que se obtivesse uma quantidade significativa de dados para se efetuar uma análise de forma mais confiável.

Notou-se, portanto, diferenças significativas no que cada partido e setor ideológico entendem por "inovação". Os percentuais de presença discursiva em cada categoria de análise variaram de forma significativa (em alguns casos mais de $30 \%$ ), o que pode indicar uma não homogeneidade da conceituação de inovação dentro do parlamento brasileiro, podendo, eventualmente, dificultar discussões em direção a esse assunto. Pela análise de cluster, percebeu-se um alinhamento partidário diferente dos mesmos partidos analisados na Câmara e no Senado. Um exemplo é o PSDB, que na Câmara teve um alinhamento maior com o DEM e no Senado teve um alinhamento maior com o PMDB e com o próprio PT (o último alinhamento pode ter sido devido ao motivo 
anteriormente explicado nos resultados e na discussão). Pode-se considerar que o posicionamento de alguns partidos apresenta certa volatilidade entre uma casa e outra. Outros exemplos a serem citados no mesmo sentido são o PP e o PSB.

Falar em espectro político pode ser um tanto subjetivo. Nas últimas décadas, assiste-se, no plano internacional, a um declínio nos níveis de identificação, na diferenciação ideológica entre os partidos, bem como na relevância dessas organizações em termos de estruturação da decisão do voto (Ribeiro et al., 2016). Tal fato também pode prejudicar a análise no sentido de criar uma estrutura estática que não pode ser alterada ao longo dos anos. No entanto, notou-se que na análise correlativa os partidos coligados têm maior proximidade, apesar do distanciamento, em teoria, no espectro ideológico.

Apesar da grande quantidade de partidos no Brasil (35) apenas os mostrados anteriormente (10) tiveram participação significativa na discussão sobre inovação. Tal fato leva a uma sugestão de repensar a significância e a importância da existência de tantos partidos que não participam ativamente da estrutura política brasileira. É importante trazer, também, de acordo com a conceituação de espectro político trazida neste artigo (extrema esquerda, centro-esquerda, centro e centro-direita), pode-se dizer que tal quantidade de partidos políticos existentes no Brasil é injustificável, uma vez que é difícil (senão impossível) pensar em 35 ideologias completamente diferentes umas das outras.

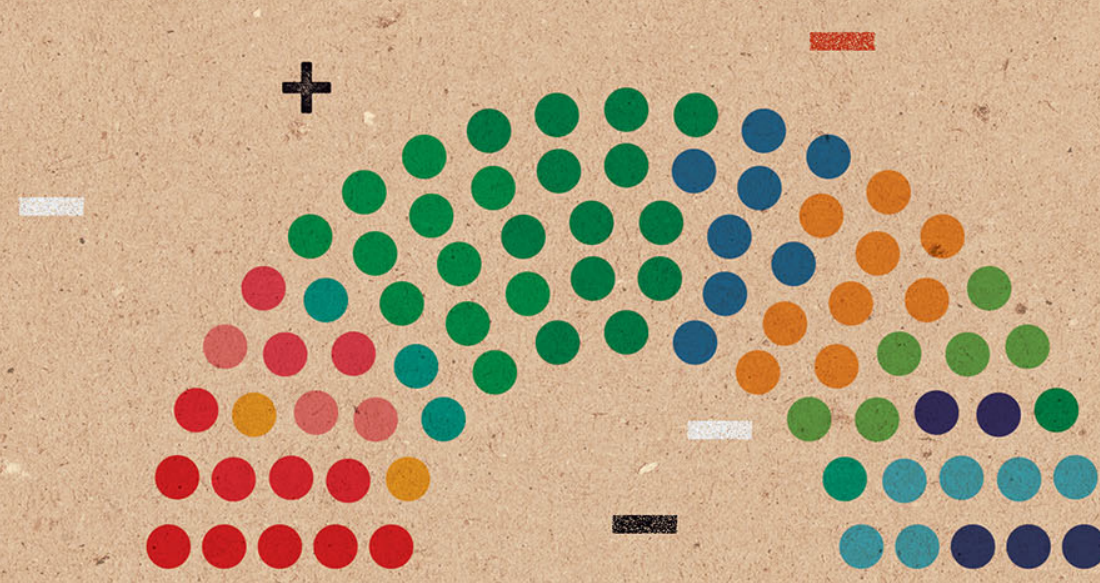


A principal contribuição deste trabalho foi trazer uma objetivação maior da discussão sobre inovação ao longo do espectro político brasileiro, trazendo os principais partidos e suas discussões a respeito de temas relacionados à inovação. Também, este trabalho trouxe de forma mais objetiva as aglomerações de cada partido a despeito de suas coligações. É importante perceber que os partidos do Brasil muitas vezes abrem mão de suas ideologias para buscarem maior influência política, como foi percebido, por exemplo, no caso do PMDB e sua relação anterior e atual com o PT e PSDB. O entendimento do alinhamento partidário se faz mais objetivo com análises da natureza das que foram feitas aqui. Com isso, pode-se ter uma ideia melhor do que se passa em cada Casa legislativa e do papel que cada partido executa na construção de uma cultura de inovação na política do país.

Quanto às limitações da pesquisa, é necessário dizer que o discurso é algo difícil de analisar de forma completamente quantitativa ou completamente qualitativa. Buscar o contexto de cada fala é importante para que não se tenham ideias errôneas a respeito do que foi proferido por um partido ou por um parlamentar. Entretanto, como os resultados indicaram certa congruência de acordo com as coligações partidárias, pode-se dizer que, de certa forma, foram fidedignos à realidade brasileira.

\footnotetext{
Notas

1 De acordo com o "Livro Verde: nossa história tal como ela é" do BNDES publicado em 2017, os desembolsos do Banco de apoio à inovação passaram de 563 milhões em 2009 para 4,5 bilhões em 2015. 2 Relatório de Gestão de Exercício de 2014 (MCTI/FINEP) e Relatório de Gestão FINEP de 2008 (MCTI/ FINEP).
}

\section{Referências}

CASSIOLATO, J. E. \& LASTRES, H. M. Celso Furtado e os dilemas da indústria e inovação no Brasil. Cadernos do Desenvolvimento, v. 10, n. 17, p. 188-213, 2018.

LASTRES, H. M.. \& CASSIOLATO, J. E. Inovação e Desenvolvimento: a força e a permanência das contribuições de Fábio Erber In: Estratégias de desenvolvimento, política industrial e inovação: ensaios emmemória de Fabio Erber. Organizadores: Dulce MONTEIRO FILHA, L. C.; DELORME PRADO, H; \& M. M. LASTRES. Rio de Janeiro, BNDES, 2014.

RIBEIRO, E. \& CARREIRÃO, Y. e BORBA, J. Sentimentos partidários e antipetismo: condicionantes e covariantes. Opinião Pública, v. 22, n. 3, p. 603-637, 2016.

SCHMIDT, V. A. From Historical Institutionalism to Discursive Institutionalism: Explaining Change in Comparative Political Economy. American Political Science Association Meetings, February, p. 25, 2008

KUHN, T. La estructura de las revoluciones científicas, Ciudad de México: Fondo de Cultura económica, 1971.

ERBER, F. Innovation and the development convention in Brazil. Revista Brasileira de Inovação, v. 3, n. 1, Jan-Jun., p. 35-54, 2004. 
SCHMIDT, V. A. Discursive Institutionalism. In: Fischer, Frank \& Gottweis, Herbert The Argumentative Turn Revisited. Durham: Duke University Press, 2012.

BRUN, G. \& BETZ, G. Analysing practical argumentation In: Hanson, Sven O. et Hadorn, Gertrude $\mathrm{H}$. (edit.). The Argumentative Turn in Policy Analysis: reasoning about uncertainty, Zurich, Springer International Publishing, 2016.

TREIB, O. Akteurzentrierter Institutionalismus. In: Wenzelburger, George \& Zohlnhöfer, Reimut (hrsg.). Handbuch Policy-Forschung, Wiesbaden, Springer Verlag, 2015.

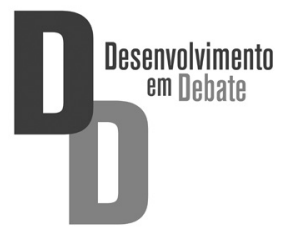

